\title{
RELATIONSHiP BETWEEN AiRWAy INFLAMMATION AND REMODELING IN Patients with Asthma and Chronic Obstructive Pulmonary Disease
}

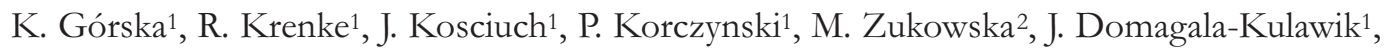 \\ M. Maskey-Warzechowska ${ }^{1}$, R. Chazan ${ }^{1}$ \\ ${ }^{1}$ Department of Internal Medicine, Pneumology and Allergology and \\ ${ }^{2}$ Second Department of Clinical Radiology, Medical University of Warsaw, Warsaw, Poland
}

\begin{abstract}
Despite a number of important differences in the pathogenesis, course and prognosis of asthma and chronic obstructive pulmonary disease (COPD), these two entities also have common features with airway inflammation being one of them. Airway remodeling is a characteristic feature of asthma, but data on the bronchial wall thickening in COPD patients are still scarce.

Aim: To assess the relation between the inflammatory cell count in the bronchoalveolar lavage fluid (BALF) and thickness of bronchial walls assessed by high resolution computed tomography (HRCT) in asthma and COPD patients.

Material and methods: The study was conducted in 9 patients with mild-to-moderate asthma (M/F 4/5, mean age $35 \pm 10$ years) and 11 patients with mild-tomoderate COPD (M/F 7/4, mean age $57 \pm 9$ years). In all subjects lung function tests and HRCT scanning of the chest were performed. External (D) and internal $(\mathrm{L})$ diameters of the airways were assessed at five selected lung levels. The lumen area $\left(A_{L}\right)$, wall area (WA), wall thickness (WT) and bronchial wall thickness (WT/D ratio) were calculated. Eight patients with asthma and 8 patients with COPD underwent fiberoptic bronchoscopy and bronchoalveolar lavage (BAL). Total and differential cell counts were assessed in the BAL fluid.

Results: Mean $\mathrm{FEV}_{1} \%$ pred was $80 \pm 19 \%$, and $73 \pm$ $20 \%$ in asthma and COPD patients, respectively (NS). No significant differences in the total and differential cell counts in BALF were found in patients with asth$\mathrm{ma}$ and COPD. There were no significant differences in the airway diameter or airway wall thickness. The mean inner airway diameter was $1.4 \pm 0.3$ and $1.2 \pm$ $0.3 \mathrm{~mm}$ and the mean lumen area was $1.8 \pm 0.7$ and $1.6 \pm 0.7 \mathrm{~mm}^{2}$ in asthma and COPD, respectively (NS). Negative correlations between the eosinophil count in BALF and inner airway diameter $(\mathrm{r}=-0.7$, $\mathrm{P}<0.05)$ and lumen area $(\mathrm{r}=-0.7, \mathrm{P}<0.05)$ were found in asthmatics. There was no significant relationship between the BALF cell count and airway wall thickness in COPD patients.

Conclusions: In mild-to-moderate asthma and COPD the airway diameter and thickness are similar. In asth-
\end{abstract}

matics, the airway diameter might be associated with eosinophil count in BAL fluid.

Key words: asthma, COPD, BALF, airway remodeling, HRCT

\section{INTRODUCTION}

The functional consequences of asthma and chronic obstructive pulmonary disease (COPD) is airflow limitations, which is easily reversible in asthma and not fully reversible in COPD. In both diseases, inflammation is associated with cellular and structural changes, referred to as remodeling, and these structural changes may lead to thickening of the airway wall; thereby, promoting airway narrowing and airflow limitation.

Various biological materials are used to assess the nature and severity of airway inflammation in patients with asthma and COPD. The most reliable data come from samples taken directly from the bronchial wall. Obtaining such materials in vivo is a relatively invasive procedure; therefore, numerous studies have investigated samples from the bronchial lumen and/or pulmonary alveoli for indirect evaluation of airway inflammation [1]. Bronchoscopy with bronchoalveolar lavage (BAL) is an important research tool in assessing airway inflammation in a variety of inflammatory lung diseases. BAL is a useful and safe research method for sampling cells and mediators from the lower airways.

High resolution computed tomography (HRCT) offers new noninvasive possibilities in the assessment of structural changes in the airways. It is useful in the quantitative (airway wall thickness) and qualitative (emphysema) assessment of airway and lung tissue remodeling in asthma [2, 3] and COPD [3, 4]. It allows to visualize the changes in airway dimensions after nonspecific challenge tests [5] and to evaluate the effects of bronchodilators [6] or the consequences of airway remodeling, e.g., air trapping [7]. A relationship between airway diameters seen in HRCT and other indices of remodeling found in bronchial biopsies and in lung function tests has been documented $[8,9]$.

Given the scarcity of publications on airway inflammation and remodelling in subjects with mild-to-moderate asthma and COPD, we decided to: (1) evaluate 
the cellular composition of bronchoalveolar lavage fluid (BALF) in patients with mild-to-moderate asthma and mild-to-moderate COPD, (2) estimate the thickening of bronchial walls by HRCT in these patients, and (3) assess the relation between the inflammatory cells count in BALF and thickness of bronchial walls assessed by HRCT in both study groups.

\section{Material ANd Methods}

The prospective study is part of a research project approved by the Bioethics Committee of the Medical University of Warsaw (No. 172/2003) and every patient had signed an informed consent form. The study included 9 subjects with mild-to-moderate asthma (4 men and 5 women) and 11 subjects with mild-to-moderate COPD ( 7 men and 4 women). Three major steps of the study were: (1) clinical and functional assessment, (2) HRCT scanning, and (3) bronchoscopy with BAL.

\section{Clinical Diagnosis and Disease Severity ASSESSMENT}

The diagnosis of asthma and COPD was based on the typical medical history and physical examination, chest radiograph, spirometry with flow-volume curve (Lung Test 1000, MES, Poland), and the bronchial obstruction reversibility test according to the guidelines of the European Respiratory Society (ERS) [10], methacholine challenge test, allergy skin prick tests and total serum IgE. The severity of asthma and COPD were assessed in accordance with the Global Initiative for Asthma (GINA) guidelines [11] and the Global Initiative for Chronic Obstructive Lung Disease (GOLD) report [1], respectively. Inclusion criteria in the asthma group were as follows: (1) signs and symptoms consistent with asthma, (2) spirometric features of airway obstruction with positive bronchial reversibility test, and (3) positive result of methacholine challenge test. Classification to the COPD group required: (1) a positive smoking history, (2) signs and symptoms consistent with COPD, and (3) a post-bronchodilator $\mathrm{FEV}_{1} / \mathrm{FVC}<70 \%$. None of the patients had been treated with inhaled or oral steroids within 3 months preceding the study. All patients were in a stable clinical condition defined as the absence of exacerbation for the last 3 months.

\section{HRCT PROCEDURE}

All subjects underwent HRCT of the chest. In order to achieve maximal bronchodilation, the procedure of CT scanning was preceded by inhalation of a shortacting beta-2 agonist (salbutamol, $400 \mu \mathrm{g}$ via a spacer). Chest CT scans were performed with a 16-row CT scanner (LightSpeed 16 General Electric, USA) using the following parameters: $1.25-\mathrm{mm}$ collimation, one second rotation $140 \mathrm{kV}$ peak, $250 \mathrm{~mA}$ current and matrix size 512 x 512. Supine, end-inspiratory scans were performed with no contrast administration. Five lung levels were selected for the assessment of the airways: (1) superior margin of the aortic arch, (2) the tracheal bifurcation, (3) $1 \mathrm{~cm}$ below the tracheal bifurcation,
(4) inferior pulmonary veins, and (5) $2 \mathrm{~cm}$ above the right hemidiaphragm. The CT image data were reconstructed with a high spatial frequency algorithm and analyzed at a window level of $-450 \mathrm{HU}$ and a window width of $1500 \mathrm{HU}$, which have been estimated as the most accurate parameters to visualize and measure the bronchial dimensions [12].

The CT images were enlarged (magnification x 10), and regions of interest were traced manually; the internal (L) and external diameters (D) were assessed by standard software analysis for distance measurement expressed in $\mathrm{mm}$ (Fig. 1). Then, cross-sections of bronchi with external diameter between $1.0 \mathrm{~mm}$ and $5.0 \mathrm{~mm}$ were identified. In order to select cross-sections perpendicular to the long airway axis the largest luminal diameter $\left(\mathrm{D}_{\mathrm{L}}\right)$ and the largest luminal diameter perpendicular to $D_{L}\left(D_{S}\right)$ were measured. Only airway cross-sections with a $\mathrm{D}_{\mathrm{L}} / \mathrm{D}_{\mathrm{S}}$ ratio $\leq 1.2$ were submitted for further analysis.

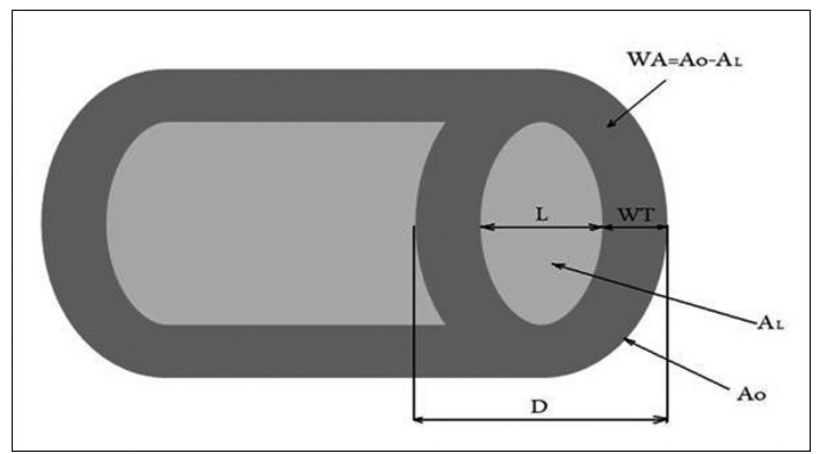

Fig. 1. Scheme of the bronchus and the parameters measured in HRCT: D - external diameter, $\mathrm{L}$ - internal (luminal) diameter, WT - wall thickness, $\mathrm{A}_{\mathrm{O}}$ - total airway area, AL - luminal area, WA - wall area.

Airway wall dimensions were measured by a radiologist blinded to the patient's diagnosis using a validated method described in earlier studies $[12,13]$. After $\mathrm{D}$ and $\mathrm{L}$ measurements, the following variables, as outlined in Fig. 1, were calculated:

1. WT - wall thickness. With the assumption that the bronchial wall thickness is constant on the cross section: $\mathrm{WT}=(\mathrm{D}-\mathrm{L}) / 2$;

2. BWT - bronchial wall thickness expressed as the ratio of wall thickness and external diameter; BWT $=$ WT/D;

3. $\mathrm{A}_{\mathrm{O}}$ (total bronchial area $)=\pi(\mathrm{D} / 2)^{2}$;

4. $A_{\mathrm{L}}$ (luminal area $)=\pi(\mathrm{L} / 2)^{2}$;

5. WA (airway wall area) $=A_{O}-A_{L}$;

6 . $\mathrm{WA} \%$ (the percentage wall area) $=\left[\mathrm{WA} / \mathrm{A}_{\mathrm{o}}\right] \mathrm{x}$ $100 \%$.

WT, BWT, WA and WA\% were used to assess airway wall thickness, while $\mathrm{D}$ and $\mathrm{A}_{\mathrm{O}}$ defined the airway caliber and $\mathrm{L}$ and $\mathrm{A}_{\mathrm{L}}$ were assumed to estimate the bronchial lumen.

\section{BRONCHOSCOPY AND BAL}

Bronchoscopy was performed under local anaesthesia (2\% lidocaine) after premedication with inhaled salbu- 
tamol $400 \mu \mathrm{g}$, atropine $0.5 \mathrm{mg}$ IM and diazepam10 mg IM. Oral route was used to introduce a flexible fiberoptic bronchoscope (11004 BC, Storz, Germany). An endotracheal tube was used to secure the upper airways and enable direct endotracheal oxygen administration. Macroscopic airway inspection and BAL were performed as described previously [14]. The volume and percentage of BAL fluid recovery was noted. The subsequent steps of BALF processing were as follows: after filtration through two layers of gauze and volume measurement, the fluid was centrifuged for 10 minutes at $300 \mathrm{x}$ g. The cell pellet was resuspended in $300 \mu \mathrm{l}$ of phosphate-buffered saline solution (PBS). Cell viability was determined by the trypan blue exclusion test. The total cell count was calculated in the Bürker chamber, while the differential cell count was performed in May-GrünwaldGiemsa stained smears (three hundred cells were counted).

\section{STATISTICAL MeTHODS}

All statistical calculations were performed using Statistica 8.0 software (StatSoft Inc., USA). Data are presented as means $\pm \mathrm{SD}$. A Mann-Whitney U-test was applied to compare two unrelated samples, while Spearman's rank correlation coefficient was utilized to test potential correlations between different variables. $\mathrm{P}<0.05$ was considered significant for all the study analyses.

\section{RESULTS}

Mild persistent asthma was diagnosed in six (67\%) and moderate asthma in the remaining three subjects. In COPD patients, the disease was classified as mild and moderate in six $(55 \%)$ and five $(45 \%)$ subjects, respectively. Mean $\mathrm{FEV}_{1} \%$ pred was $80 \pm 19 \%$ in asthma and $73 \pm 20 \%$ in COPD (NS). The patients' characteristics and lung function parameters are shown in Table 1.

Table 1. Demographic and lung function data of the study groups.

\begin{tabular}{|c|c|c|c|}
\hline Variable & $\begin{array}{c}\text { Asthma } \\
\mathrm{n}=9\end{array}$ & $\begin{array}{l}\text { COPD } \\
\mathrm{n}=11\end{array}$ & $\mathrm{P}$ \\
\hline $\begin{aligned} & \text { Gender }(\mathrm{n}) \\
& \text { female } \\
& \text { male }\end{aligned}$ & $\begin{array}{l}5 \\
4\end{array}$ & $\begin{array}{l}4 \\
7\end{array}$ & $\begin{array}{l}\text { NS } \\
\text { NS }\end{array}$ \\
\hline Age (yr) & $36 \pm 10$ & $57 \pm 9$ & $<0.05$ \\
\hline $\mathrm{BMI}\left(\mathrm{kg} / \mathrm{m}^{2}\right)$ & $24.3 \pm 3.2$ & $26.7 \pm 5.1$ & NS \\
\hline Smoking history $\mathrm{n}(\%)$ & $3(45)$ & $11(100)$ & $<0.05$ \\
\hline Pack-years (in current and former smokers) & $8.1 \pm 16.4$ & $40.2 \pm 13.0$ & $<0.05$ \\
\hline Onset of symptoms (age) & $15 \pm 14$ & $53 \pm 10$ & $<0.05$ \\
\hline Duration of symptomatic illness (yr) & $21 \pm 3$ & $4 \pm 11$ & $<0.05$ \\
\hline Atopy n $(\%)$ & $7(78)$ & $1(9)$ & $<0.05$ \\
\hline $\mathrm{PC}_{20}(\mathrm{mg} / \mathrm{ml})$ & $3.7 \pm 5.8$ & $10.7 \pm 7.8$ & $<0.05$ \\
\hline $\mathrm{FEV}_{1} \%$ pred & $80 \pm 19$ & $73 \pm 20$ & NS \\
\hline FVC \%pred & $100 \pm 14$ & $102 \pm 25$ & NS \\
\hline $\mathrm{FEV}_{1} \% \mathrm{FVC}$ & $66 \pm 9$ & $58 \pm 5$ & $<0.05$ \\
\hline RV \%pred & $132 \pm 23$ & $158 \pm 40$ & NS \\
\hline $\mathrm{DL}_{\mathrm{CO}} \%$ pred & $84 \pm 15$ & $60 \pm 18$ & $<0.05$ \\
\hline
\end{tabular}

Table 2. Comparison of the total and differential cell count of BALF in asthma and COPD patients.

\begin{tabular}{|c|c|c|c|}
\hline Variable & $\begin{array}{c}\text { Asthma BALF } \\
(\mathrm{n}=8)\end{array}$ & $\begin{array}{c}\text { COPD BALF } \\
(\mathrm{n}=8)\end{array}$ & $\mathrm{P}$ \\
\hline Total cell count $\left(\mathrm{x} 10^{6}\right.$ cells $\left./ \mathrm{ml}\right)$ & $12.0 \pm 13.5$ & $20.0 \pm 13.3$ & NS \\
\hline Neutrophils (\%) & $6 \pm 3$ & $5 \pm 2$ & NS \\
\hline Neutrophils (x $10^{6}$ cells /ml) & $0.7 \pm 0.8$ & $0.9 \pm 0.6$ & NS \\
\hline Lymphocytes (\%) & $16 \pm 16$ & $19 \pm 14$ & NS \\
\hline Lymphocytes (x $10^{6}$ cells $/ \mathrm{ml}$ ) & $3.5 \pm 7.9$ & $3.5 \pm 3.9$ & NS \\
\hline Eosinophils (\%) & $3 \pm 3$ & $1 \pm 2$ & NS \\
\hline Eosinophils (x $10^{6}$ cells $/ \mathrm{ml}$ ) & $0.6 \pm 1.1$ & $0.4 \pm 0.9$ & NS \\
\hline Macrophages (\%) & $75 \pm 17$ & $75 \pm 15$ & NS \\
\hline Macrophages (x $10^{6}$ cells $/ \mathrm{ml}$ ) & $7.2 \pm 4.3$ & $15.1 \pm 10.4$ & NS \\
\hline
\end{tabular}


Table 3. Comparison of the mean airway dimensions in asthma and COPD patients.

\begin{tabular}{l|c|c|c}
\hline Variable & $\begin{array}{c}\text { Asthma } \\
(\mathrm{n}=9)\end{array}$ & $\begin{array}{c}\text { COPD } \\
(\mathrm{n}=11)\end{array}$ & P \\
\hline Outer airway diameter - D (mm) & $3.1 \pm 0.7$ & $2.7 \pm 0.4$ & $\mathrm{NS}$ \\
Internal airway diameter - L (mm) & $1.4 \pm 0.3$ & $1.3 \pm 0.3$ & $\mathrm{NS}$ \\
Luminal area - AL (mm $\left.{ }^{2}\right)$ & $1.8 \pm 0.7$ & $1.6 \pm 0.7$ & $\mathrm{NS}$ \\
Wall area - WA (mm $\left.{ }^{2}\right)$ & $6.7 \pm 2.7$ & $4.9 \pm 1.3$ & $\mathrm{NS}$ \\
Wall thickness - WT (mm) & $0.9 \pm 0.2$ & $0.7 \pm 0.1$ & $\mathrm{NS}$ \\
Bronchial wall thickness (WT/D ratio) & $0.28 \pm 0.02$ & $0.27 \pm 0.02$ & $\mathrm{NS}$ \\
The percentage wall area (WA $\%)$ & $79 \pm 4$ & $78 \pm 3$ & $\mathrm{NS}$ \\
\hline
\end{tabular}

\section{Cellular Composition of BALF}

The mean volume of the BALF samples was 107.5 $\pm 15.5 \mathrm{ml}$ in asthma patients and $106.2 \pm 15.0 \mathrm{ml}$ in COPD patients (NS). An analysis of the total cell count and cellular composition showed no significant differences between asthma and COPD patients (Table 2). BALF from COPD patients contained a higher number of cells than BALF from subjects with asthma, but the difference was insignificant. In both groups, macrophages predominated in BALF, accounting for about $75 \%$ of all cells. The percentage of eosinophils was higher in the asthma group compared with COPD, but the difference was insignificant (Table 2).

\section{AIRWAY DIMENSIONS IN HRCT}

The mean number of bronchial cross-sections evaluated per patient was similar in asthma (25 \pm 6$)$ and COPD $(29 \pm 6)$. The number of measurements taken in the right and left lung was also comparable $(14 \pm 2$ in asthma vs. $13 \pm 3$ in COPD; NS). At each of five evaluated lung levels $5 \pm 2$ bronchi were measured.

The HRCT analysis showed no significant differences in the measured airway diameters in both study groups. The mean inner airway diameter was $1.4 \pm 0.3$ $\mathrm{mm}$ in asthma, and $1.2 \pm 0.3 \mathrm{~mm}$ in COPD (NS), the mean lumen area was $1.8 \pm 0.7 \mathrm{~mm}^{2}$ and $1.6 \pm 0.7 \mathrm{~mm}^{2}$, respectively (NS). The mean values of airway wall thickness parameters (WT, BWT, WA, and WA\%) in asthma patients were similar to those in COPD patients, WA and WT were slightly higher in the asthma group, but the differences were not significant (Table 3).

\section{Correlations of the BALF Cell Count with the AIRWAY DIMENSIONS IN HRCT}

Negative correlations between the eosinophil count in BALF and inner airway diameter $(\mathrm{r}=-0.7, \mathrm{P}<0.05)$ and lumen area $(\mathrm{r}=-0.7, \mathrm{P}<0.05)$ were found in asthmatics. There were no significant relationships between the BALF cell count and airway wall thickness in COPD patients.

\section{Discussion}

Airway remodeling refers to changes in the airway structure and includes subepithelial fibrosis, increased smooth muscle mass, submucosal gland enlargement, revascularization, and epithelial alterations. Remodeling is observed in response to chronic airway injury and is seen not only in asthma but also in other respiratory diseases. For many years, the analysis of the inflammatory process within the airways and their remodeling was possible mainly in post-mortem studies. Bronchoscopic forceps biopsy samples are a valuable source of information on the structural changes, but they do not allow evaluating the whole bronchial wall. Visualization of the airway wall by computed tomography and endobronchial ultrasound (EBUS) has offered new possibilities in the assessment of these phenomena. A great advantage of CT is its minimal invasiveness, and thus it has become a useful and authentic tool for airway imaging.

\section{HRCT FINDINGS}

In the present study, the dimensions of the airways were similar in asthma and COPD patients in mild-tomoderate disease. The mean indices of wall thickness and wall area tended to be slightly higher in asthmatic compared with COPD airways, but the difference did not reach statistical significance $(\mathrm{P}=0.06$ for $\mathrm{WA}$ and 0.057 for W'T).

The authors were unable to find studies directly comparing the quantitative features of airway remodeling in asthma and COPD with the help of CT. There were few studies comparing the airways of healthy subjects and asthmatics and of healthy subjects and COPD patients. The results of those studies strongly suggest significant airway thickening in both childhood and adult asthma. Airway wall thickening was observed in HRCT studies not only in mild, moderate, and severe asthma $[8,9,15,16]$, but also in patients without significant airway obstruction (coughvariant asthma) [17]. Airway wall thickening was also reported in COPD patients $[4,18]$. Airway remodeling and increased bronchial wall thickness was observed in mild COPD and even in asymptomatic smokers [4]. Some studies have shown that in healthy subjects the bronchial wall thickness ranges between 0.18 and $0.23 \mathrm{~mm}$, and the range for the percent wall area $(\mathrm{WA} \%$ ) is between 44 to $70 \%[8,9,16,18]$. The mean values of BWT and WA\% in our patients were similar to those in other studies involving patients with asthma and COPD. Thus, we can only speculate indirectly that the mean BWT and WA\% 
values found in our asthma and COPD patients were probably higher than those observed in healthy subjects $[4,8]$.

The lack of significant differences between asthmatic and COPD airways assessed by HRCT might be a result of the small number of patients studied. Another potential reason for such results is the inability of HRCT to show histopathological changes in the airway wall. Differences and similarities between airway remodeling in these diseases have been described. Epithelial injury and early thickening of the reticular basement membrane are highly characteristic for the asthmatic airways. Thickening of the airway wall, goblet cell hyperplasia, mucous gland hypertrophy, and the luminal obstruction caused by inflammatory exudates and mucus are features of both asthma and COPD. Increases in the airway smooth muscle mass occur in large airways of severe asthmatics and in small airways of patients with COPD. Squamous epithelial metaplasia and airway wall fibrosis are commonly observed in COPD. Destruction and fibrosis of the alveolar wall occur in COPD, but not in asthma. Since HRCT is not able to recognize and discriminate these pathological features, the asthmatic and COPD airways might have a similar appearance. Disease severity might be also a factor influencing the results of our study. When interpreting the results, it should be remembered that more than $50 \%$ of the patients with asthma and COPD had mild disease. It is possible that in these patients airway remodeling was in its early phase and thus difficult to detect.

We would like to emphasize that we made efforts to eliminate all the factors, which could influence the study results. First, we applied an approved method of airway dimension assessment, described in detail by McNamara et al. [8] and Awadh et al. [12]. In order to obtain the optimal visualization of the bronchial wall and luminal area, we used technical parameters reported to be the most appropriate in bronchial dimension CT assessment $[8,12,19]$. To eliminate some reversible causes of airway obstruction and to achieve maximal bronchodilation, patients inhaled a short acting b2-agonist prior to the HRCT procedure.

\section{Cellular Composition of BALF}

In the present study the total count and cellular BALF composition showed no significant differences between asthma and COPD patients in mild-to-moderate stage. The results were not entirely as we had expected. Although we did not demonstrate significant differences in the cellular composition of BALF between asthma and COPD patients, there were some typical trends for both study groups. BALF from COPD patients tended to have a higher number of cells than BALF from asthma patients, and there was a tendency towards a higher BALF eosinophil count in asthmatics, but both differences did not reach statistical significance. The results of a previous study conducted in greater groups (22 asthma patients, 17 COPD patients) showed a significantly higher BALF total cell count in COPD patients when compared with asthmatics [14]. As in the present study, macro- phages were the predominant cell population in both diseases, accounting for $75 \%$ of the total cell count. Nevertheless, the absolute macrophage count was significantly higher in COPD patients, whereas the proportion of eosinophils was significantly higher in patients with asthma [14].

In our attempts to explain the similarity of the BALF cellular composition in asthma and COPD patients we rejected the simplest hypothesis, which assumed incorrect assignment of the clinical diagnosis to individual patients. We feel that this is justified, because special attention was paid during the recruitment in order to counter any objections to the correctness of the diagnosis.

By adopting a sufficiently long period (of at least 3 months) of no anti-inflammatory treatment preceding the enrolment to the study as an eligibility criterion, we eliminated the potential effect of medication on inflammation. This criterion was essential, given the fact that our aim was to evaluate airway inflammatory cells in the natural course of the disease, as the effect of corticosteroid treatment (even brief) on inflammatory markers and on the structural changes in the airways is commonly recognized [20].

\section{ReLATIONSHip BETWEen BALF CELls AND Airway DiAMETERS IN HRCT}

In the present study, negative correlations between the BALF eosinophil count and the inner airway diameter and lumen area were found in asthmatics. This, in our opinion, is an interesting finding. It may lead to the conclusion that a smaller airway lumen could be associated with an increased number of eosinophils in asthmatic BALF. BALF reflects the changes in the airway lumen itself and, therefore, provides only indirect information about airway remodeling. We did not observe any significant relationship between the BALF cell count and the airway wall thickness measured in HRCT.

In patients with COPD, no significant correlations between the BALF cell count and airway dimensions measured in HRCT were noted. Since we were unable to find any other reports comparing inflammatory cells in BALF with airway dimensions using HRCT in asthma and COPD patients, we could not confront our finding with the results of other studies.

Airway inflammation and remodeling are considered to be two, generally independent processes. Immunohistochemical and molecular studies suggest that the mechanisms leading to the structural changes in the airway wall involve complex interactions between epithelial and mesenchymal cells through multiple cytokines and growth factors. Studies on the so-called epithelial mesenchymal trophic unit (EMTU), defined by Holgate in 2000, indicate that one of the main causes of remodeling is the impaired repair of the damaged airway epithelium [21].

Reticular basement membrane (BM) thickness (related mainly to excessive collagen and matrix deposition), which may be assessed in bronchial mucosa biopsy, is an early symptom of remodeling in asthma. The results of our previous study demonstrated no relationship between BM thickness and the total and dif- 
ferential cell count in BALF from asthma patients [22]. Kasahara et al. [9] were probably the first authors to demonstrate the relationship between BM thickness in bronchial mucosa biopsy and the airway dimensions measured in HRCT. We were unable to find many reports dealing with this issue. Moreover, some data suggest that measurements of BWT on HRCT cannot be used as a surrogate marker for BM thickness in endobronchial biopsies [23].

There are some limitations to our study. A small number of patients studied is one of the most important. The main limiting factors affecting sample sizes was the requirement not to use corticosteroids in the pre-study period and patient's consent to exposure to a relatively high radiation dose during HRCT and to bronchoscopy. This is partially compensated by the number of airways analyzed; 225 in the asthma and 319 in the COPD groups.

The fact that the measurements were performed by one radiologist only may also be considered as a drawback. However, the interpretation of the radiological image and all the measurements were consulted with a pulmonologist. Moreover, previous studies also involved one radiologist only [16]. It seems that the results obtained in studies in which one radiologist interpreted the CT scans are comparable to those involving two specialists $[4,8,16,23,24]$.

In conclusion, in mild-to-moderate asthma and COPD the airway diameter and thickness are similar. The airway diameter in asthmatics might be associated with eosinophil count in BAL fluid.

Conflicts of interest: No conflicts of interest were declared by the authors of this work.

\section{REFERENCES}

[1] Global Initiative for Chronic Obstructive Lung Disease. Global Strategy for the Diagnosis, Management and Prevention of Chronic Obstructive Pulmonary Disease. NHLBI/WHO workshop report. 2008.

[2] Capraz F, Kunter E, Cermik H, Ilvan A, Pocan S. The effect of inhaled budesonide and formoterol on bronchial remodeling and HRCT features in young asthmatics. Lung 2007; 185: 89-96.

[3] Harmanci E, Kebapci M, Metintas M, Ozkan R. High-resolution computed tomography findings are correlated with disease severity in asthma. Respiration 2002; 69: 4206.

[4] Deveci F, Murat A, Turgut T, Altunta_ E, Muz MH. Airway wall thickness in patients with COPD and healthy current smokers and healthy non-smokers: assessment with high resolution computed tomographic scanning. Respiration 2004; 71: 602-10.

[5] Amirav I, Kramer SS, Grunstein MM, Hoffman EA. Assessment of methacholine-induced airway constriction by ultrafast high-resolution computed tomography. J Appl Physiol 1993; 75: 2239-50.

[6] Beigelman-Aubry C, Capderou A, Grenier PA, Straus C, Becquemin $\mathrm{MH}$, Similowski T, Zelter M. Mild intermittent asthma: CT assessment of bronchial cross-sectional area and lung attenuation at controlled lung volume. Radiology 2002; 223: 181-7.

[7] Laurent F, Latrabe V, Raherison C, Marthan R, Tunon-deLara JM. Functional significance of air trapping detected in moderate asthma. Eur Radiol 2000; 10: 1404 10 .
[8] Awadh N, Müller NL, Park CS, Abboud RT, Fitzgerald JM. Airway wall thickness in patients with near fatal asthma and control groups: assessment with high resolution computed tomographic scanning. Thorax 1998; 53: 24853.

[9] Kasahara K, Shiba K, Ozawa T, Okuda K, Adachi M. Correlation between the bronchial subepithelial layer and whole airway wall thickness in patients with asthma. Tho$\operatorname{rax} 2002$; 57: 242-6.

[10] Standardized lung function testing. Official statement of the European Respiratory Society. Eur Respir J Suppl 1993; 16: 1-00.

[11] GINA Global Initiative for Asthma: Global strategy for asthma management and prevention. NHLBI/WHO. 2002.

[12] McNamara AE, Müller NL, Okazawa M, Arntorp J, Wiggs BR, Paré PD. Airway narrowing in excised canine lungs measured by high-resolution computed tomography. J Appl Physiol 1992; 73: 307-16.

[13] Okazawa M, Müller N, McNamara AE, Child S, Verburgt L, Paré PD. Human airway narrowing measured using high resolution computed tomography. Am J Respir Crit Care Med 1996; 154: 1557-62.

[14] Gorska K, Krenke R, Domagala-Kulawik J, Korczynski P, Nejman-Gryz P, Kosciuch J, Hildebrand K, Chazan R. Comparison of cellular and biochemical markers of airway inflammation in patients with mild-to-moderate asthma and chronic obstructive pulmonary disease: an induced sputum and bronchoalveolar lavage fluid study. J Physiol Pharmacol 2008; 59 Suppl 6: 271-83.

[15] Gono H, Fujimoto K, Kawakami S, Kubo K. Evaluation of airway wall thickness and air trapping by HRCT in asymptomatic asthma. Eur Respir J 2003; 22: 965 71.

[16] Niimi A, Matsumoto H, Amitani R, Nakano Y, Mishima M, Minakuchi M, Nishimura K, Itoh H, Izumi T. Airway wall thickness in asthma assessed by computed tomography. Relation to clinical indices. Am J Respir Crit Care Med 2000; 162: 1518-23.

[17] Matsumoto H, Niimi A, Tabuena R P, Takemura M, Ueda T, Yamaguchi M, Matsuoka H, Jinnai M, Chin K, Mishima M. Airway wall thickening in patients with cough variant asthma and nonasthmatic chronic cough. Chest 2007; 131: 1042-9.

[18] Nakano Y, Muro S, Sakai H, Hirai T, Chin K, Tsukino M, Nishimura K, Itoh H, Paré PD, Hogg JC, Mishima M. Computed tomographic measurements of airway dimensions and emphysema in smokers. Correlation with lung function. Am J Respir Crit Care Med 2000; 162: 11028.

[19] Mclean AN, Sproule MW, Cowan MD, Thomson NC. High resolution computed tomography in asthma. Tho$\operatorname{rax} 1998$; 53: 308-14.

[20] Currie GP, Syme-Grant NJ, McFarlane LC, Carey FA, Lipworth BJ. Effects of low dose fluticasone/salmeterol combination on surrogate inflammatory markers in moderate persistent asthma. Allergy 2003; 58: 602-7.

[21] Holgate ST, Davies DE, Lackie PM, Wilson SJ, Puddicombe SM, Lordan L. Epithelial-mesenchymal interactions in the pathogenesis of asthma. J Allergy Clin Immunol 2000; 105: 193-204.

[22] Górska K, Krenke R, Kosciuch J, Przybylowski T, Domagala-Kulawik J, Hildebrand K, Baran W, Kujawa M, Chazan R. The relationship between markers of airway inflammation and thickness of the basement membrane in patients with asthma. Pneumonol Alergol Pol 2007; 75(4): 363-9 (Article in Polish).

[23] Saglani S, Papaioannou G, Khoo L, Ujita M, Jeffery PK, Owens C, Hansell DM, Payne DN, Bush A. Can HRCT be used as a marker of airway remodelling in children with difficult asthma? Respir Res 2006; 7: 46. 
[24] Little SA, Sproule MW, Cowan MD, Macleod KJ, Robertson M, Love JG, Chalmers GW, McSharry CP, Thomson NC. High resolution computed tomographic assessment of airway wall thickness in chronic asthma: reproducibility and relationship with lung function and severity. Tho$\operatorname{rax} 2002 ; 57: 247-53$.
Corresponding author:

Katarzyna Górska, MD, PhD

Department of Internal Medicine, Pneumology and Allergology Medical University of Warsaw

Banacha 1a St.

02-091 Warsaw, Poland

Phone: +48501077180

Fax: $\quad+48225991560$

E-mail: Kpgorska@wp.pl 